\title{
Total Factor Environmental Productivity in the Mediterranean Countries: A Malmquist-Luenberger Index Approach
}

\author{
Eya Jebali, $\mathrm{PhD}$ \\ University of Tunis, Tunis, Tunisia \\ (iD https://orcid.org/0000-0002-1847-113X \\ Hédi Essid, $\mathrm{PhD}$ \\ University of Tunis, Tunis, Tunisia \\ (iD) https://orcid.org/0000-0002-3989-1571 \\ Contact: jebalieya@yahoo.fr
}

\begin{abstract}
This article examines the environmental productivity in the Mediterranean countries over the period 20092014.We use the Malmquist-Luenberger productivity index that can handle undesirable outputs within data envelopment analysis approach. We decompose the index into technical efficiency, technological change, and scale efficiency change to determine the source of productivity changes. Empirical findings indicate that the total factor environmental productivity in the Mediterranean countries have a negative developmental trend. Furthermore, we find that technological progress is the main source of productivity growth. Finally, Mediterranean countries need a considerable effort on research and development to optimize the potential for technical development and enhance the environmental efficiency levels.
\end{abstract}

Keywords: $\mathrm{CO}_{2}$ emissions; DEA; DDF; Malmquist-Luenberger index; Mediterranean countries; productivity

Date Submitted: March 21, 2019 | Date Published: May 27, 2020

\section{Recommended Citation}

Jebali, E., \& Essid, H. (2020). Total factor environmental productivity in the Mediterranean countries: A MalmquistLuenberger index approach. International Journal of Applied Management and Technology, 19, 62-76. https://doi.org/10.5590/IJMAT.2020.19.1.05

\section{Introduction}

Nowadays, with the fast development of emerging economies and the exponential increase in energy consumption, the achievement of economic welfare and sustainable development have become central focuses in the world because energy consumption is strongly related to greenhouse gas emissions. Therefore, the question of energy efficiency has become a popular international topic.

In order to monitor energy efficiency trends and compare the performance of energy efficiency across countries, several methods have been developed. These methods are usually classified as parametric and nonparametric ones (Zhou et al., 2012). In the parametric methods such as Stochastic frontier analysis, a cost 
or production function is estimated. In the nonparametric methods such as data envelopment analysis (DEA), it is not necessary to estimate the cost or production function. Frontier methods are beneficial in terms of allowing comparisons with the best observed performance by constructing a best practice frontier based on empirical data. From the existing frontier methods, DEA is often used in energy efficiency studies due to its greater flexibility to handle multiple inputs and outputs (Mardani et al., 2016).

As mentioned by Aziz et al. (2013), the DEA technique evaluates the relative efficiency of a homogeneous set of decision-making units (DMUs) in their use of multiple inputs to produce multiple outputs using linear programming. Conventional DEA models assume that output indicators are good (desirable), they are measured on a scale for which the highest values correspond to better performance. Meanwhile, in the energy field, both desirable and undesirable outputs indicators may be present. $\mathrm{CO}_{2}$ emissions can be generated by the energy conversion of fossil fuels. In this case, the efficiency of a specific DMU is defined as being better than that of others if it produces more desirable outputs and fewer undesirable outputs given the same amount of inputs, Chiu (2012) assigned this definition to the environmental efficiency. In this regard, several approaches have been offered to handle undesirable outputs into DEA such as the directional distance function (DDF). It is firstly developed by Chambers (1996) and then extended by Chung et al. (1997) to incorporate undesirable outputs in the model. The advantage of the DDF method is that it allows expanding desirable outputs while contracting the undesirable outputs. For this reason, the application of DDF is popular than the other approaches. In addition, it is widely applied in energy efficiency analysis as mentioned in N. Zhang and Choi (2014).

According to Jebali et al. (2017), several studies have been conducted in the literature to assess environmental efficiency across regions or countries. However, this issue has never been discussed in the context of Mediterranean countries despite the fact that these countries will encounter several environmental problems in the future. In this regard, Giorgi (2006), De Durrieu et al. (2011), and Diffenbaugh and Giorgi (2012) pointed out that the Mediterranean region will be notably affected by climate change. Furthermore, according to the European Investment Bank (2008), in 2025 the $\mathrm{CO}_{2}$ emissions due to energy use will be twice as high as they were in 1990. Consequently, a main question arises: Are Mediterranean countries in the way of reducing $\mathrm{CO}_{2}$ emissions and producing more economic output?

To answer the above question, it is necessary to study the environmental productivity in the Mediterranean countries. According to Kaneko and Managi (2004), environmental productivity is defined as the most efficient utilization of pollution abatement technologies. In other words, the environmental productivity analyzes a country's efficiency in its use of energy and its impact on the environment such as greenhouse gas emissions. In addition, Kaneko and Managi reported that productivity improvement can play an important role in addressing environmental problems. Therefore, the purpose of our study is to assess the environmental productivity in the Mediterranean countries.

To measure productivity, several indices have been proposed in the literature. The most well-known index is the Malmquist productivity index (MPI) which is initially defined by Malmquist (1953), then developed by Caves et al. (1982). Despite the fact that the MPI offers a more complete picture of productivity growth as pointed out by Boussemart et al. (2003), it does not consider the undesirable outputs. To overcome this issue, Chung et al. (1997) developed the Malmquist-Luenberger productivity index (MLPI) based on DDFs that takes into consideration simultaneously the desirable and undesirable outputs. The MLPI has been widely used in environmental productivity studies (e.g., Arabi et al., 2017; Bampatsou \& Halkos, 2018; Jeon \& Sickles, 2004; Kumar, 2006; Li et al., 2018; Liu et al., 2018; Monastyrenko, 2017; Munisamy \& Arabi, 2015; Shen et al., 2019; Song et al., 2017; Wang et al., 2013; Wei et al., 2019; Yörük \& Zaim, 2005; C. Zhang et al., 2011). In this article, we use the MPLI to evaluate the total factor environmental productivity in the Mediterranean countries from 2009 to 2014. 
Usually, as the MPI, the MLPI is decomposed into efficiency change (EFFCH) and technological efficiency change (TECH) to identify the source of productivity change. In this article, we extend the Ray and Desli (1997) MPI decomposition into the MLPI to pick up the effect of scale efficiency on productivity change.

To the best of our knowledge, there has been no study that has examined the environmental productivity in the context of Mediterranean countries. Hence, our article is intended to fill this gap. This study is the first one examining environmental productivity in the Mediterranean countries in a quantitative manner. The previous studies associated to environmental issues in these countries include the work of Vilén and Fernandes (2011), Garcia-Hurtado et al. (2013), Sanz-Cobena et al. (2014), Fernando et al. (2017), Zrelli (2017), Kahouli (2018), and Mbarek et al. (2018), among others.

\section{Methodology}

Assume that there are $j=1, \ldots, n$ DMUs over $t=1, \ldots, T$ time periods. Each DMU uses the input vector $x^{t} \in \mathbb{R}_{+}^{m}$ to jointly obtain a set of desirable outputs denoted by the vector $y^{t} \in \mathbb{R}_{+}^{s}$ and a set of undesirable outputs denoted by the vector $u^{t} \in \mathbb{R}_{+}^{b}$. The production technology can be expressed as follows:

$$
\Psi^{t}=\left\{\left(x^{t}, y^{t}, u^{t}\right): x^{t} \text { can produce } y^{t} \text { and } u^{t}\right\}
$$

Some key assumptions are required when modeling production technology: First the undesirable outputs are weakly disposable (N. Zhang, Bing, \& Zhongfei, 2016; N. Zhang, Bing, Zhu, 2016). This assumption states that the reduction of undesirable outputs would incur a reduction in desirable outputs. Second, the desirable outputs are freely disposable. Third, the desirable outputs are null joint with the undesirable ones (Oh, 2010). This implies that desirable outputs cannot be produced without the production of undesirable output as well.

For two consecutive time periods, $t_{1}$ and $t_{2}$ consider the output oriented DDF observed at period $t$, which can be either $t_{1}$ or $t_{2}$ but evaluated with respect to technology $t_{1}$, as follows:

$$
\vec{D}^{t_{1}}\left(x^{t}, y^{t}, u^{t} ; g\right)=\max \left\{\beta \mid\left(x^{t}, y^{t}+\beta g_{y}, u^{t}-\beta g_{u}\right) \in \Psi^{t_{1}}\right\}, t=t_{1}, t_{2}
$$

where $g=\left(g_{y}, g_{u}\right)$ is the vector of the directions in which the desirable and undesirable outputs should be scaled. In Equation 2, $\beta$ represents the scaling factor by which desirable outputs are increased while undesirable outputs are decreased. The DDF denoted $\vec{D}^{t_{2}}$ with respect to period $t_{2}$ is defined in a similar way.

The true DDF must be estimated from the available data because it cannot be directly observed. To do so, we use the DEA method to estimate it. See Jebali et al. (2017) for further discussion on the DEA technique.

Considering the dataset as $\left\{\left(x_{j}^{t}, y_{j}^{t}, u_{j}^{t}\right), j=1, \ldots, n\right\}$, we use DEA to envelop data to estimate the production sets and to examine the efficiency of DMUs (Mediterranean countries). Under the constant returns to scale (CRS) assumption with respect to period $t$, the empirical production possibility set is defined as follows:

$$
\begin{aligned}
\hat{\Psi}_{c r s}^{t}=\left\{\left(x^{t}, y^{t}, u^{t}\right) \in \mathbb{R}_{+}^{m+s+b} \mid x^{t}\right. & \geq \sum_{j=1}^{j=n} \lambda_{j} x_{j}^{t}, y^{t} \leq \sum_{j=1}^{j=n} \lambda_{j} y_{j}^{t}, \\
u^{t} & \left.=\sum_{j=1}^{j=n} \lambda_{j} u_{j}^{t}, \lambda_{j} \geq 0, \forall j=1, \ldots, n\right\}
\end{aligned}
$$

Under the variable returns to scale (VRS) assumption with respect to time period $t$, the empirical production possibility set is expressed as follows: 


$$
\begin{aligned}
\hat{\Psi}_{v r s}^{t}=\left\{\left(x^{t}, y^{t}, u^{t}\right) \in \mathbb{R}_{+}^{m+s+b} \mid x^{t}\right. & \geq \sum_{j=1}^{j=n} \lambda_{j} x_{j}^{t}, y^{t} \leq \sum_{j=1}^{j=n} \lambda_{j} y_{j}^{t}, \\
u^{t} & \left.=\sum_{j=1}^{j=n} \lambda_{j} u_{j}^{t}, \sum_{j=1}^{j=n} \lambda_{j}=1, \lambda_{j} \geq 0, \forall j=1, \ldots, n\right\}
\end{aligned}
$$

For a given set of the technology at period $t_{1}$, the estimator of the DDF, under $k=C R S$ or VRS scale assumptions, for an arbitrary $\mathrm{DMU}_{\mathrm{o}}$ observed at period $t$, is defined by

$$
\overrightarrow{\hat{D}}_{k}^{t_{1}}\left(x_{0}^{t}, y_{0}^{t}, u_{0}^{t} ; g\right)=\max \left\{\beta \mid\left(x_{0}^{t}, y_{0}^{t}+\beta y_{0}^{t}, u_{0}^{t}-\beta u_{0}^{t}\right) \in \hat{\Psi}_{k}^{t_{1}}\right\}, k=C R S, V R S \text { and } t=t_{1}, t_{2}
$$

The estimator $\overrightarrow{\hat{D}}_{k}^{t_{2}}$ is obtained by substituting $t_{1}$ by $t_{2}$ in Equation 5 . In order to assess the environmental productivity across Mediterranean countries, we use the output oriented MLPI defined by Chung et al. (1997) based on DDF to account for undesirable outputs. The MLPI measures the productivity changes between two time periods $t_{1}$ and $t_{2}$ where $t_{1}<t_{2}$. It is defined as the geometric mean of two ratios of DDFs as follows:

$$
\operatorname{MLPI}\left(x^{t_{1}}, y^{t_{1}}, u^{t_{1}}, x^{t_{2}}, y^{t_{2}}, u^{t_{2}}\right)=\left[\frac{1+\vec{D}_{c r s}^{t_{1}}\left(x^{t_{1}}, y^{t_{1}}, u^{t_{1}}\right)}{1+\vec{D}_{c r s}^{t_{1}}\left(x^{t_{2}}, y^{t_{2}}, u^{t_{2}}\right)} \times \frac{1+\vec{D}_{c r s}^{t_{2}}\left(x^{t_{1}}, y^{t_{1}}, u^{t_{1}}\right)}{1+\vec{D}_{c r s}^{t_{2}}\left(x^{t_{2}}, y^{t_{2}}, u^{t_{2}}\right)}\right]^{1 / 2}
$$

Similar to the MPI, the MLPI can be decomposed into three components: EFFCH, TECH, and scale efficiency change (SECH) as follows:

$$
\begin{aligned}
\operatorname{EFFCH}\left(x^{t_{1}}, y^{t_{1}}, u^{t_{1}}, x^{t_{2}}, y^{t_{2}}, u^{t_{2}}\right)= & \frac{1+\vec{D}_{v r s}^{t_{1}}\left(x^{t_{1}}, y^{t_{1}}, u^{t_{1}}\right)}{1+\vec{D}_{v r s}^{t_{2}}\left(x^{t_{2}}, y^{t_{2}}, u^{t_{2}}\right)} \\
\operatorname{TECH}\left(x^{t_{1}}, y^{t_{1}}, u^{t_{1}}, x^{t_{2}}, y^{t_{2}}, u^{t_{2}}\right)= & {\left[\frac{1+\vec{D}_{v r s}^{t_{2}}\left(x^{t_{2}}, y^{t_{2}}, u^{t_{2}}\right)}{1+\vec{D}_{v r s}^{t_{1}}\left(x^{t_{2}}, y^{t_{2}}, u^{t_{2}}\right)} \times \frac{1+\vec{D}_{v r s}^{t_{2}}\left(x^{t_{1}}, y^{t_{1}}, u^{t_{1}}\right)}{1+\vec{D}_{v r s}^{t_{1}}\left(x^{t_{1}}, y^{t_{1}}, u^{t_{1}}\right)}\right] } \\
\operatorname{SECH}\left(x^{t_{1}}, y^{t_{1}}, u^{t_{1}}, x^{t_{2}}, y^{t_{2}}, u^{t_{2}}\right)=\{ & {\left[\frac{1+\vec{D}_{v r s}^{t_{1}}\left(x^{t_{2}}, y^{t_{2}}, u^{t_{2}}\right) / 1+\vec{D}_{c r s}^{t_{1}}\left(x^{t_{2}}, y^{t_{2}}, u^{t_{2}}\right)}{1+\vec{D}_{v r s}^{t_{1}}\left(x^{t_{1}}, y^{t_{1}}, u^{t_{1}}\right) / 1+\vec{D}_{c r s}^{t_{1}}\left(x^{t_{1}}, y^{t_{1}}, u^{t_{1}}\right)}\right] } \\
& \left.\times\left[\frac{1+\vec{D}_{v r s}^{t_{2}}\left(x^{t_{2}}, y^{t_{2}}, u^{t_{2}}\right) / 1+\vec{D}_{c r s}^{t_{2}}\left(x^{t_{2}}, y^{t_{2}}, u^{t_{2}}\right)}{1+\vec{D}_{v r s}^{t_{2}}\left(x^{t_{1}}, y^{t_{1}}, u^{t_{1}}\right) / 1+\vec{D}_{c r s}^{t_{2}}\left(x^{t_{1}}, y^{t_{1}}, u^{t_{1}}\right)}\right]\right\}^{1 / 2}
\end{aligned}
$$

The product of the above components equals $\operatorname{MLPI}\left(x^{t_{1}}, y^{t_{1}}, u^{t_{1}}, x^{t_{2}}, y^{t_{2}}, u^{t_{2}}\right)$.

The first component, defined in Equation 7, measures the TECH between $t_{1}$ and $t_{2}$ with respect to a variable returns to scale technology. It captures how close a DMU (country) moves toward a contemporaneous benchmark technology at time period $t_{2}$ compared to time period $t_{1}$. An $E F F C H>1(<1)$ corresponds to efficiency gain (loss). The second component, in Equation 8, is the geometric mean of technological change over the same period. If a contemporaneous benchmark technology frontier shifts in the direction of more (less) desirable outputs and less (more) undesirable outputs, then TECH $>1(<1)$. The last component, 
defined in Equation 9, measures the contribution of the returns to scale to the productivity change between $t_{1}$ and $t_{2}$. An improvement in productivity between $t_{1}$ and $t_{2}$ is marked by $M L P I>1$ and a decrease in productivity between $t_{1}$ and $t_{2}$ by $M L P I<1$. If $M L P I=1$, then the productivity is constant.

The calculation of the MLPI requires the calculation of distance functions. The DDFs are computed as the solutions to linear programming (LP) problems. Eight problems must be solved for each observation. Four problems are solved in which all the observations are from the same period ( $t_{1}$ and $t_{2}$, respectively) under both return to scale assumptions (CRS and VRS). For instance, for an arbitrary $\mathrm{DMU}_{0}$ at period $t_{1}$ under CRS assumption:

$$
\begin{array}{ll}
\overrightarrow{\hat{D}}_{c r s}^{t_{1}}\left(x_{0}^{t_{1}}, y_{0}^{t_{1}}, u_{0}^{t_{1}}\right)=\max \beta & \\
\text { s.t } \sum_{j=1}^{n} \lambda_{j}^{t_{1}} x_{i j}^{t_{1}} \leq x_{i 0}^{t_{1}}, & i=1, \ldots, m \\
\sum_{j=1}^{n} \lambda_{j}^{t_{1}} y_{k j}^{t_{1}} \geq(1+\beta) y_{k 0}^{t_{1}}, & k=1, \ldots, s \\
\sum_{j=1}^{n} \lambda_{j}^{t_{1}} u_{l j}^{t_{1}}=(1-\beta) u_{l 0}^{t_{1}}, & l=1, \ldots, b \\
\lambda_{j}^{t_{1}} \geq 0, & j=1, \ldots, n
\end{array}
$$

Under VRS assumption we have:

$$
\begin{array}{ll}
\overrightarrow{\hat{D}}_{v r s}^{t_{1}}\left(x_{0}^{t_{1}}, y_{0}^{t_{1}}, u_{0}^{t_{1}}\right)=\max \beta & i=1, \ldots, m \\
s . t & \sum_{j=1}^{n} \lambda_{j}^{t_{1}} x_{i j}^{t_{1}} \leq x_{i 0}^{t_{1}}, \quad \\
\sum_{j=1}^{n} \lambda_{j}^{t_{1}} y_{k j}^{t_{1}} \geq(1+\beta) y_{k 0}^{t_{1}}, \quad k=1, \ldots, s \\
\sum_{j=1}^{n} \lambda_{j}^{t_{1}} u_{l j}^{t_{1}}=(1-\beta) u_{l 0}^{t_{1}}, \quad l=1, \ldots, b \\
\sum_{j=1}^{n} \lambda_{j}^{t_{1}}=1 \\
\lambda_{j}^{t_{1}} \geq 0, \quad j=1, \ldots, n
\end{array}
$$

$\overrightarrow{\hat{D}}_{c r s}^{t_{2}}\left(x_{0}^{t_{2}}, y_{0}^{t_{2}}, u_{0}^{t_{2}}\right)$ and $\overrightarrow{\hat{D}}_{v r s}^{t_{2}}\left(x_{0}^{t_{2}}, y_{0}^{t_{2}}, u_{0}^{t_{2}}\right)$ are obtained in the same way by substituting $t_{1}$ by $t_{2}$ in Problems 10 and 11 , respectively.

The other four problems are mixed period ones under both return to scale assumptions (CRS and VRS). The DDF for $\mathrm{DMU}_{\mathrm{o}}$ at period $t_{2}$ using period $t_{1}$ technology under the crs assumption can be calculated by solving the following LP problem: 


$$
\begin{array}{cc}
\overrightarrow{\hat{D}}_{c r s}^{t_{1}}\left(x_{0}^{t_{2}}, y_{0}^{t_{2}}, u_{0}^{t_{2}}\right)=\max \beta & i=1, \ldots, m \\
\text { s.t } \sum_{j=1}^{n} \lambda_{j}^{t_{1}} x_{i j}^{t_{1}} \leq x_{i 0}^{t_{2}}, & \\
\sum_{j=1}^{n} \lambda_{j}^{t_{1}} y_{k j}^{t_{1}} \geq(1+\beta) y_{k 0}^{t_{2}}, & k=1, \ldots, s \\
\sum_{j=1}^{n} \lambda_{j}^{t_{1}} u_{l j}^{t_{1}}=(1-\beta) u_{l 0}^{t_{2}}, & l=1, \ldots, b \\
\lambda_{j}^{t_{1}} \geq 0, & j=1, \ldots, n
\end{array}
$$

Under the vrs assumption:

$$
\begin{array}{ll}
\overrightarrow{\hat{D}}_{v r s}^{t_{1}}\left(x_{0}^{t_{2}}, y_{0}^{t_{2}}, u_{0}^{t_{2}}\right)=\max \beta & i=1, \ldots, m \\
\text { s.t } \sum_{j=1}^{n} \lambda_{j}^{t_{1}} x_{i j}^{t_{1}} \leq x_{i 0}^{t_{2}}, & \\
\sum_{j=1}^{n} \lambda_{j}^{t_{1}} y_{k j}^{t_{1}} \geq(1+\beta) y_{k 0}^{t_{2}}, \quad k=1, \ldots, s \\
\sum_{j=1}^{n} \lambda_{j}^{t_{1}} u_{l j}^{t_{1}}=(1-\beta) u_{l 0}^{t_{2}}, \quad l=1, \ldots, b \\
\sum_{j=1}^{n} \lambda_{j}^{t_{1}}=1 \\
\lambda_{j}^{t_{1}} \geq 0, & j=1, \ldots, n
\end{array}
$$

$\overrightarrow{\hat{D}}_{c r s}^{t_{2}}\left(x_{0}^{t_{1}}, y_{0}^{t_{1}}, u_{0}^{t_{1}}\right)$ and $\overrightarrow{\hat{D}}_{v r s}^{t_{2}}\left(x_{0}^{t_{1}}, y_{0}^{t_{1}}, u_{0}^{t_{1}}\right)$ are obtained in the same way by substituting $t_{1}$ by $t_{2}$ in Problems 12 and 13 , respectively.

\section{Data}

The input variables include energy consumption (petajoules), labor force (thousand people), and gross fixed capital formation (GFCF; billion USD). The Gross Domestic Product (GDP; billion USD) is the good (desirable) output while a $\mathrm{CO}_{2}$ emission (kt) is the undesirable output. GFCF and GDP are measured in purchasing power parity. Data on energy consumption during the period 2009-2014 are gathered from the 2012 and 2014 energy statistics yearbooks. The energy statistics yearbook is a collection of international energy statistics developed annually by the United Nations Statistics Division. The statistics cover production, trade, transformation, and final consumption (end-use) for a range of primary and secondary energy products derived from conventional and non-conventional or renewable energy sources. Data on labor force, GFCF, GDP, and $\mathrm{CO}_{2}$ emissions are collected from the World Development Indicators, which presents the most current and accurate global development data available, and includes national, regional, and global estimates.

Descriptive statistics on inputs and outputs from 2009 to 2014 are shown in Table 1. 
Table 1. Descriptive Statistics of Inputs and Outputs (2009-2014)

\begin{tabular}{lcccc}
\hline \multicolumn{1}{c}{ Variable } & $\boldsymbol{M}$ & $\boldsymbol{S D}$ & Min & Max \\
\hline Energy consumption & $1,112.61$ & $1,682.65$ & 15 & 6674 \\
GFCF & 93.29351 & 142.9408 & 2.1123 & 576.0790 \\
Labor & $8,223.82$ & $9,991.42$ & 172.3560 & $30,183.77$ \\
GDP & 434.4910 & 679.6957 & 10.6540 & $2,583.31$ \\
$\mathrm{CO}_{2}$ emissions & $87,905.09$ & $113,785.59$ & 28.8300 & $405,361.20$
\end{tabular}

Note. GFCF = gross fixed capital formation; GDP = Gross Domestic Product.

\section{Results and Discussions}

In this study, we use the MLPI to assess environmental productivity in the Mediterranean countries over the period 2009-2014. As mentioned by Du et al. (2018), the main limitation of MLPI is the infeasibility problem in computing the cross-period DDFs. Therefore, all results given in this section are computed for countries with feasible solution.

Figures below display the productivity index as well as its components for each period. We begin by Figure 1 which shows that the highest growth rate was $8.07 \%$ and was recorded by Croatia. This productivity growth was due to $9.37 \%$ technical efficiency gain and $0.02 \%$ scale efficiency gain. However, Albania recorded the worst productivity rate $(3.62 \%)$.

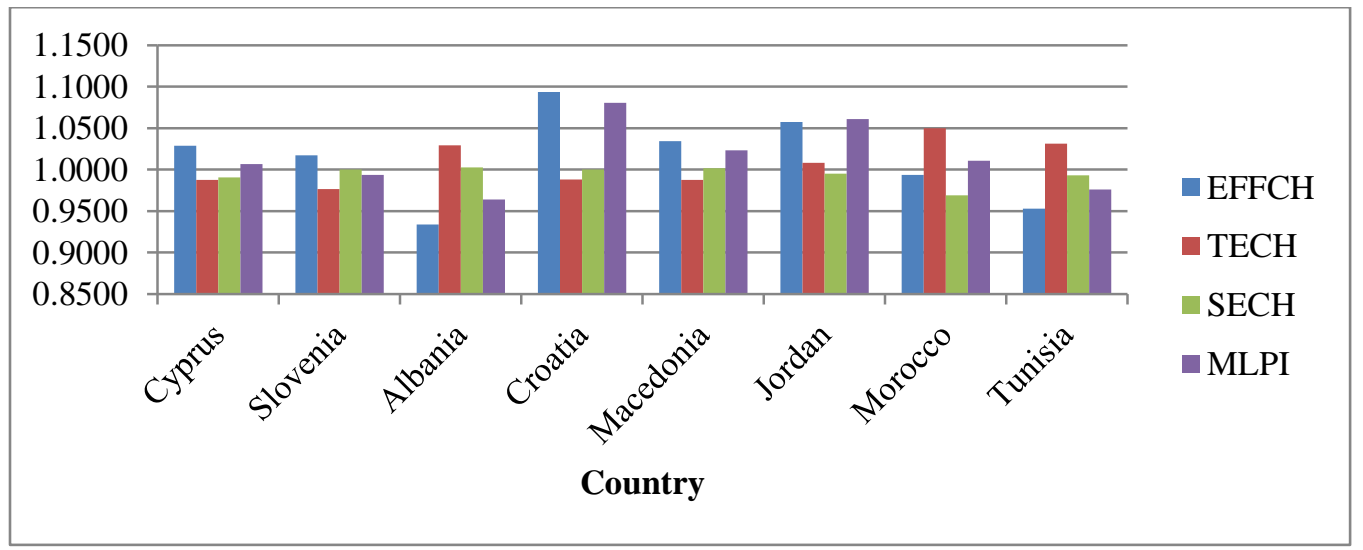

Figure 1. Malmquist-Luenberger Productivity Index and Its Components Over 2009-2010. EFFCH = efficiency change; $T E C H$ = technical change; $S E C H=$ scale efficiency change.

Figure 2 indicates that five countries out of 10 (with feasible solution) have shown productivity gains and five have shown productivity losses. The greatest productivity gain was recorded by Slovenia (7.21\%). This growth was the result of technical efficiency gain of the order of $2.83 \%$ and technological gain of the order of $4.33 \%$. The worst productivity rate was recorded by Israel (6.46\%). This environmental productivity deterioration was due to technical efficiency regression of the order of $25.61 \%$. 


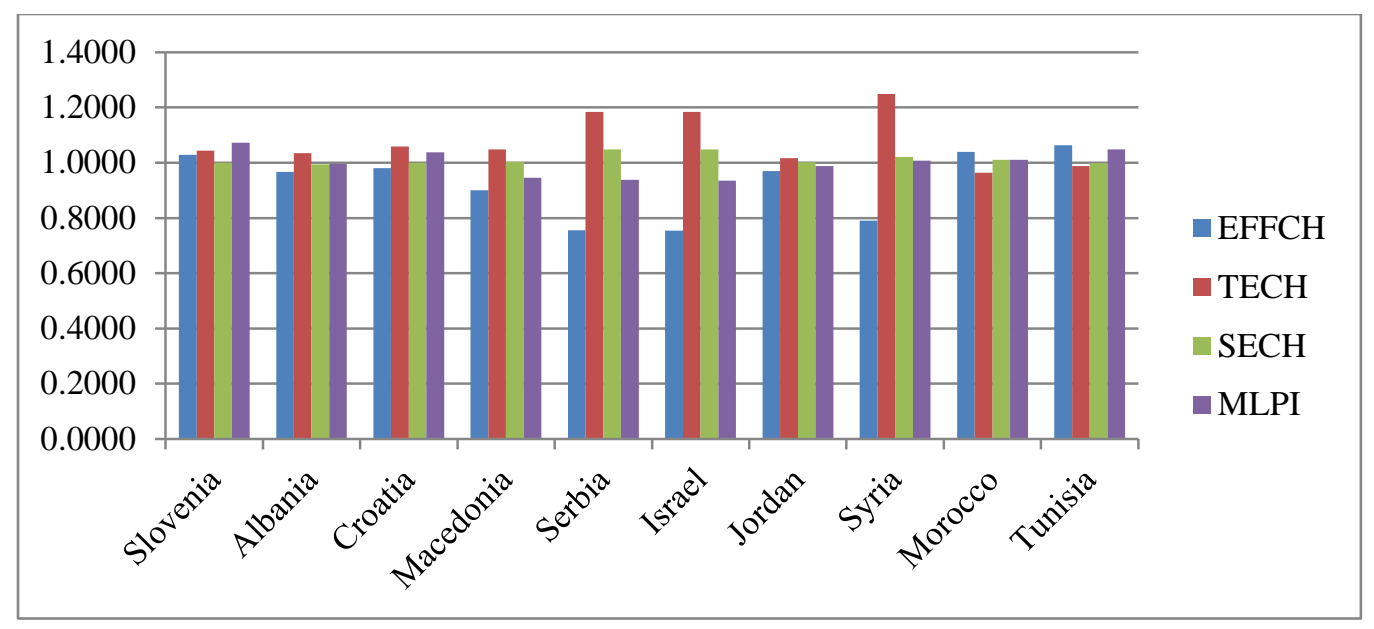

Figure 2. Malmquist-Luenberger Productivity Index and Its Components Over 2010-2011. EFFCH = efficiency change; TECH = technical change; $S E C H=$ scale efficiency change.

Figure 3 depicts that seven countries out of nine were characterized by increased productivity between 2011 and 2012 where Albania recorded the highest productivity gain of the order of 10.53\%. Technical efficiency gain contributed to this productivity growth by $10.77 \%$ while technological improvement contributed by $0.78 \%$.

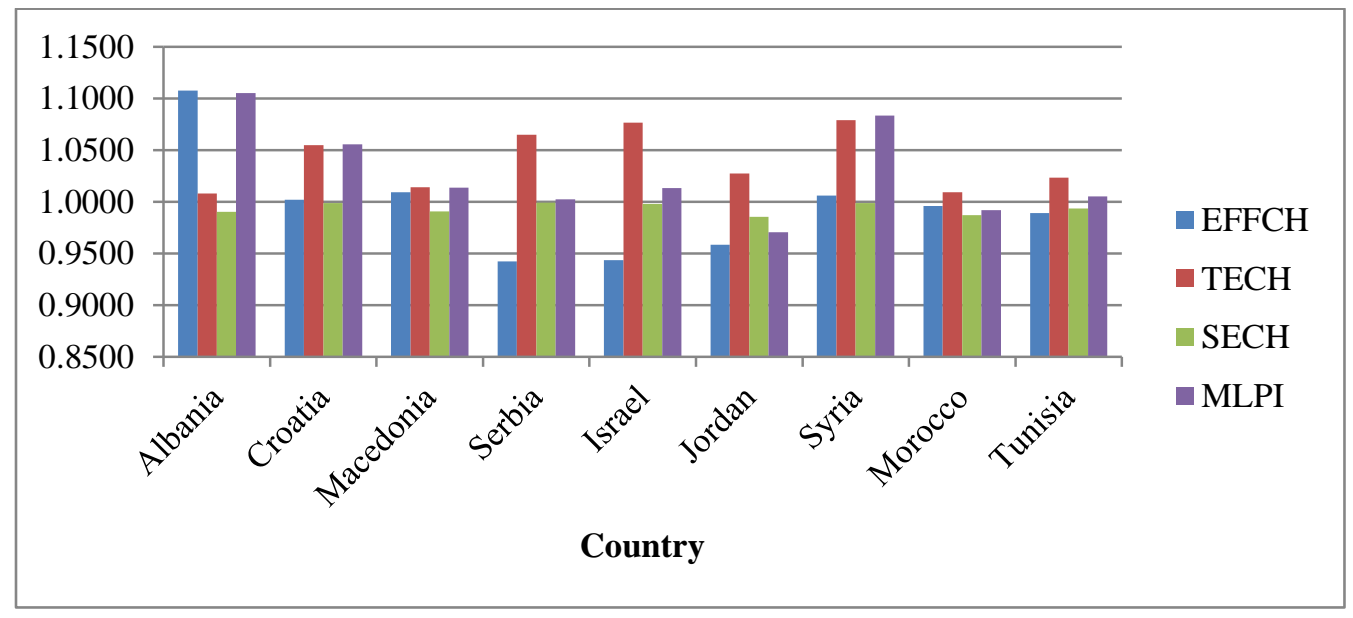

Figure 3. Malmquist-Luenberger Productivity Index and Its Components Over 2011-2012. EFFCH = efficiency change; TECH = technical change; $S E C H=$ scale efficiency change.

Figure 4 shows that eight countries out of nine experienced environmental productivity gain. The highest growth rate was recorded by Israel (7.82\%) while Albania witnessed productivity deterioration of the order of $5.6 \%$. 


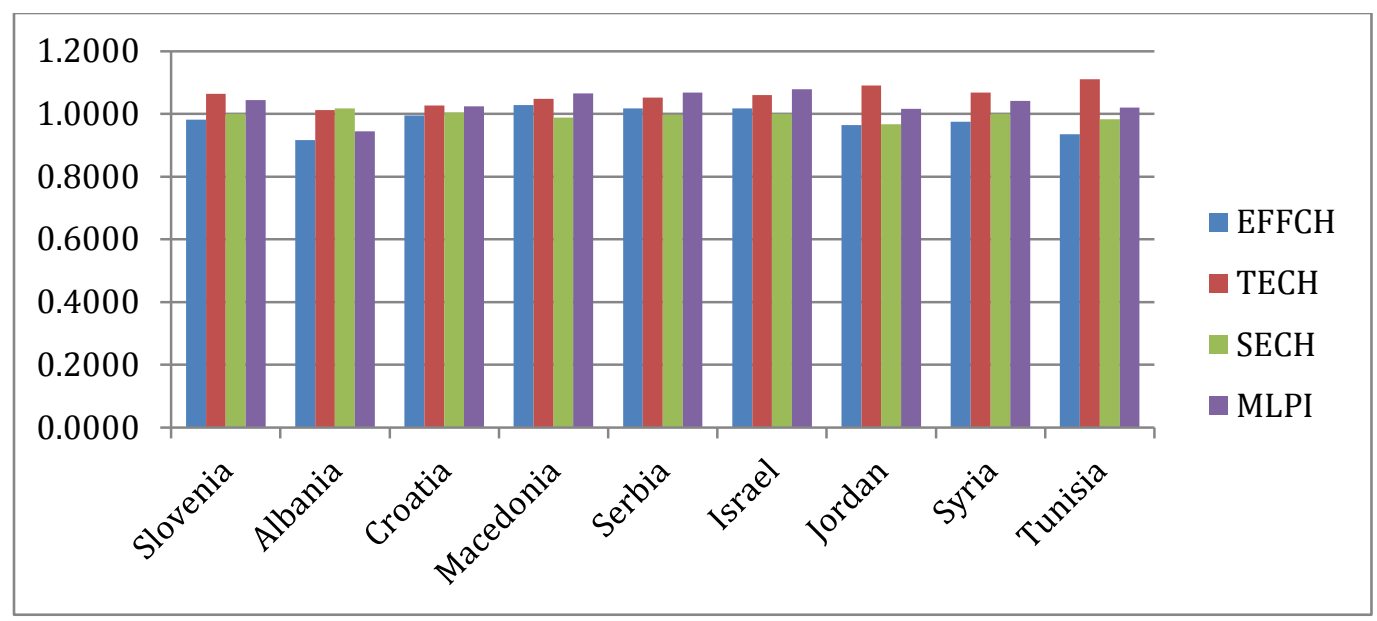

Figure 4. Malmquist-Luenberger Productivity Index and Its Components Over 2012-2013. EFFCH = efficiency change; $T E C H$ = technical change; $S E C H=$ scale efficiency change.

Finally, Figure 5 shows that only two countries (Serbia and Israel) out of 10 are characterized by increased environmental productivity. Syria recorded productivity deterioration of the order of $25.62 \%$ with a technical efficiency regress of $26.19 \%$.

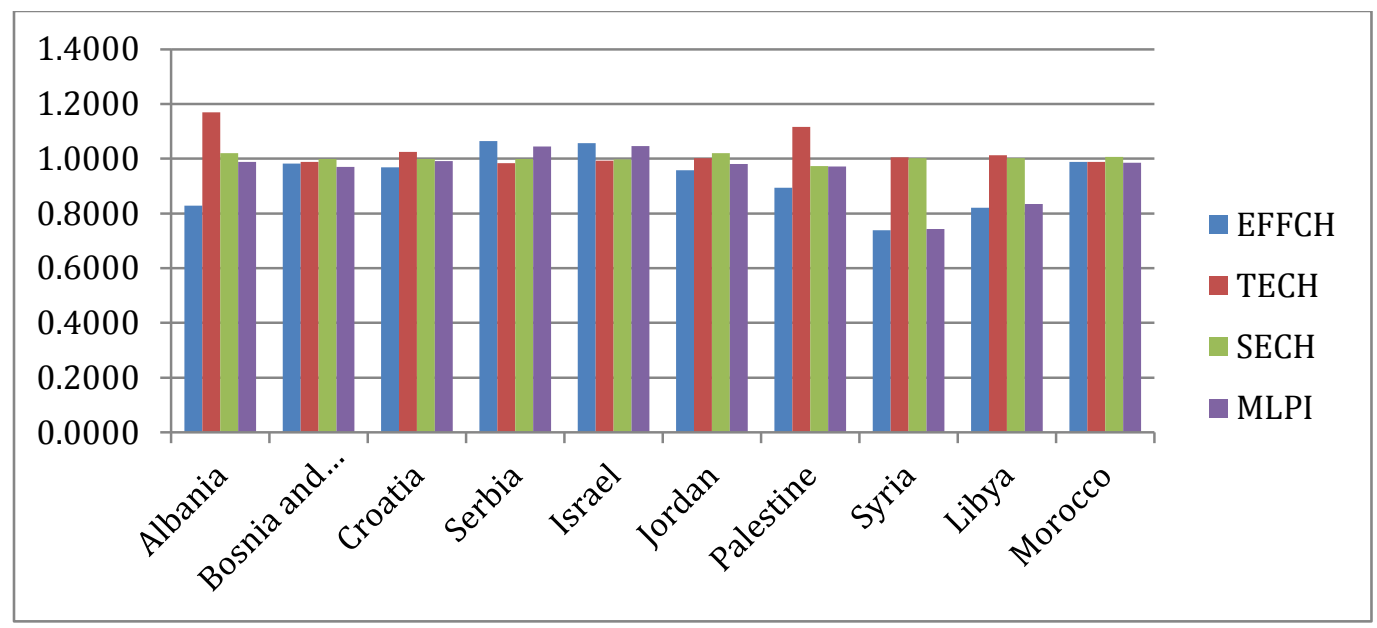

Figure 5. Malmquist-Luenberger Productivity Index and Its Components Over 2013-2014. EFFCH = efficiency change; TECH = technical change; $S E C H=$ scale efficiency change.

Results suggest that Mediterranean countries performed an effort to enhance their productivity levels from a period to another. However, in the last period of study several countries witnessed environmental productivity deterioration. In fact, $\mathrm{CO}_{2}$ emissions reduction in the Mediterranean remains a critical issue. Initiatives undertaken in favor of carbon constraint need to be supported and smartly organized to maintain the momentum of reduction policies launched in northern and southern countries to take measures.

Table 2 reports the results of the average productivity. This table shows that the environmental productivity of Mediterranean countries slightly increased by an average of $0.36 \%$. In addition, Table 2 indicates that the 
main source of productivity growth in these countries is the technical component, which increased by almost 4.07\% while the EFFCH component decreased by 3.5\%. With regards to scale efficiency, we note that its value is much closer to one indicating that the scale efficiency has likely stagnated. Also, Table 2 demonstrates that the total factor environmental productivity has significantly declined between 2013 and 2014.

Table 2. Average Productivity and Its Components

\begin{tabular}{llccc}
\hline \multicolumn{1}{c}{ Year } & MLPI & EFFCH & TECHCH & SECH \\
\hline $2009-2010$ & 1.0138 & 1.0128 & 1.0070 & 0.9941 \\
$2010-2011$ & 0.9969 & 0.9177 & 1.0733 & 1.0122 \\
$2011-2012$ & 1.0258 & 0.9937 & 1.0392 & 0.9934 \\
$2012-2013$ & 1.0328 & 0.9804 & 1.0585 & 0.9950 \\
$2013-2014$ & 0.9508 & 0.9243 & 1.0267 & 1.0018 \\
Average & 1.0036 & 0.9650 & 1.0407 & 0.9992 \\
\hline
\end{tabular}

Note MLPI = Malmquist-Luenberger productivity index; $\mathrm{EFFCH}=$ efficiency change; $\mathrm{TECH}=$ technical change; $\mathrm{SECH}=$ scale efficiency change.

Thereafter in Table 3, we report the cumulative MLPI indices and their decompositions from 2009 to 2014. As depicted here, eight countries (Cyprus, Slovenia, Croatia, Macedonia, Serbia, Israel, Jordan, and Tunisia) experienced productivity growth on average. Croatia attained the highest productivity growth rate (3.74\%) followed by Slovenia (3.62\%). As a matter of fact, the energy efficiency in Croatia is guided by incentives for investments into energy-efficient products through diverse environmental taxes, including pollution fees and environmental user fees. In addition, productivity growth in Slovenia was the result of energy efficiency subsidies and efforts to move toward the green tax reform. Also, six countries experienced productivity declines on average with Libya (16.57\%) having the lowest productivity growth rates. A possible explanation of this result is the Libyan civil war in 2011 which led to a much more significant decline of GDP than that of emissions.

As the MLPI is a multiplicative composite of $\mathrm{EFFCH}, \mathrm{TECH}$, and $\mathrm{SECH}$, the main source of productivity improvements can be established by comparing the values of these indexes. In other words, the productivity increase can be the result of efficiency improvement or technological progress or scale efficiency increase or all of them. On the basis of decomposition of the productivity growth rate, findings above show that technical change is the main component of productivity increase. For example, Slovenia's environmental productivity growth was the result of $0.89 \%$ efficiency gain and $2.73 \%$ technological gain. While the productivity growth in Croatia was the result of $0.67 \%$ efficiency gain, 3.01\% technological progress and $0.03 \%$ scale efficiency improvement. However, Libya experienced a technological improvement of $1.29 \%$ but, this rate was insufficient to enhance the environmental productivity. 
Table 3. Average MLPI by Country From 2009 and 2014

\begin{tabular}{lcccc}
\hline \multicolumn{1}{c}{ Country } & MLPI & EFFCH & TECH & SECH \\
\hline Cyprus & 1.0067 & 1.029 & 0.9876 & 0.9906 \\
Slovenia & 1.0362 & 1.0089 & 1.0273 & 0.9997 \\
Albania & 0.9977 & 0.9466 & 1.0491 & 1.0046 \\
Bosnia and Herzegovina & 0.9697 & 0.9827 & 0.9878 & 0.999 \\
Croatia & 1.0374 & 1.0067 & 1.0301 & 1.0003 \\
Macedonia & 1.0112 & 0.9914 & 1.0245 & 0.9956 \\
Serbia & 1.0144 & 0.9368 & 1.0707 & 1.0113 \\
Israel & 1.0140 & 0.9258 & 1.0610 & 1.0013 \\
Jordan & 1.0026 & 0.9812 & 1.0281 & 0.9938 \\
Palestine & 0.9709 & 0.8936 & 1.1166 & 0.9731 \\
Syria & 0.9589 & 0.8695 & 1.0966 & 1.0057 \\
Libya & 0.8343 & 0.8215 & 1.0129 & 1.0027 \\
Morocco & 0.9995 & 1.004 & 1.0023 & 0.9931 \\
Tunisia & 1.012 & 0.9839 & 1.0371 & 0.9918 \\
\hline
\end{tabular}

Note. MLPI = Malmquist-Luenberger productivity index; $\mathrm{EFFCH}$ = efficiency change; $\mathrm{TECH}$ = technical change; $\mathrm{SECH}=$ scale efficiency change.

To test the difference between the MLPI and its components, we use the nonparametric Kruskal-Wallis test. The results of the test are given in Table 4, which indicates that there is no significant difference between the MLPI and its components.

Table 4. Kruskal-Wallis Test Result for the Malmquist-Luenberger Productivity Index (MLPI) and Its Components

\begin{tabular}{|c|c|c|c|}
\hline MLPI & EFFCH & TECH & SECH \\
\hline$\chi^{2}$ & 13 & 13 & 13 \\
\hline$p$ & 0.3690 & 0.3690 & 0.3690 \\
\hline
\end{tabular}

Note . $\mathrm{EFCH}=$ efficiency change; $\mathrm{TECH}=$ technical change; $\mathrm{SECH}=$ scale efficiency change.

\section{Conclusion}

In this study, the levels of environmental productivity for Mediterranean countries over the period of 20092014 were studied using the MLPI. The main contribution of this article is the use of this approach in the context of Mediterranean countries. Findings indicate that the total factor environmental productivity has a negative developmental trend. This shows that clean energy targets in the Mediterranean region were unstable.

The decomposition of MLPI into its components showed that the improvements due to technological change have been significant, whereas the improvements due to changes in the EFFCH and SECH have been modest. Hence, we can conclude that future growth in Mediterranean countries will depend on a considerable effort on research and development to optimize the potential for technical development. Research and development is essential to develop and test new equipment and system development in the energy sector. 
In order to improve the total factor environmental productivity in the Mediterranean region, we suggest some policy measures. First, strengthen regional cooperation as a key tool for achieving a stable environmental and economic balance. Second, promote collaborative research among Mediterranean countries on aspects of technology and management. Third, induce industries with high $\mathrm{CO}_{2}$ emissions to reduce their emissions and to move toward clean production. Fourth, take advantage of natural resources in the Mediterranean region such as solar energy and wind to achieve a green growth. As an extension to this work, we suggest the use of the global MLPI as recommended by Emrouznejad and Yang (2016) to analyze the productivity of Mediterranean countries with infeasibility problems.

\section{References}

Arabi, B., Munisamy, S., Ali, D., \& Khoshroo, A. (2017). Eco-efficiency measurement and material balance principle: An application in power plants Malmquist Luenberger Index. Annals of Operations Research, 255(1-2), 221-239. https://doi.org/10.1007/s10479-015-1970-x

Aziz, N. A. A., Janor, R. M., \& Mahadi, R. (2013): Comparative departmental efficiency analysis within a university: A DEA approach. Procedia Social and Behavioral Sciences, 90, 540-548.

Bampatsou, C., \& Halkos, G. (2018). Dynamics of productivity taking into consideration the impact of energy consumption and environmental degradation. Energy Policy, 120, 276-283. https://doi.org/10.1016/j.enpol.2018.05.039

Boussemart, J., Briec, W., Kerstens, K., \& Poutineau, J. (2003). Luenberger and Malmquist productivity indices: Theoretical comparisons and empirical illustration. Bulletin of Economic Research, 55(4), 391-405. https://doi.org/10.1111/1467-8586.00183

Caves, D. W., Christensen, L. R., \& Diewert, E. (1982). The economic theory of index numbers and the measurement of inputs outputs and productivity. Econometrica, 5o(6), 393-1414.

Chambers, R. G. (1996). Benefit and distance functions. Journal of Economic Theory, 419(70), 407-419. https://doi.org/10.1016/j.socscimed.2012.04.010

Chiu, C., Liou, J., Wu, P., \& Fang, C. (2012). Decomposition of the environmental inefficiency of the metafrontier with undesirable output. Energy Economics, 34(5), 1392-1399. https://doi.org/10.1016/j.eneco.2012.06.003

Chung, Y. H., Färe R., \& Grosskopf, S. (1997). Productivity and undesirable outputs: A directional distance function approach. Journal of Environmental Management, 51(3), 229-240. https://doi.org/10.1006/jema.1997.0146

De Durrieu., M., Guieu, C., Sempéré, R., Conan, P., Cossa, D., Ortenzio, F. D., . . Verney, R. (2011). Marine ecosystems' responses to climatic and anthropogenic forcings in the Mediterranean. Progress in Oceanography, 91(2), 97-166. https://doi.org/10.1016/j.pocean.2011.02.003

Diffenbaugh, N. S., \& Giorgi, F. (2012). Climate change hotspots in the CMIP5 global climate model ensemble. Climatic Change, 114, 813-822. https://doi.org/10.1007/s10584-012-0570-x

Du, J., Chen, Y., \& Huang, Y. (2018). A modified Malmquist-Luemberger productivity index: Assessing environmental productivity perforance in China. European Journal of Operational Research, 269(1), 171-187. https://doi.org/10.1016/j.ejor.2017.01.006

European Investment Bank. (2008). Study on climate change and energy in the Mediterranean. http://www.eib.org/attachments/country/climate change energy mediterranean en.pdf 
Emrouznejad, A., \& Yang, G. (2016). A framework for measuring global MalmquisteLuenberger productivity index with $\mathrm{CO}_{2}$ emissions on Chinese manufacturing industries. Energy, 115, 840-856. https://doi.org/10.1016/j.energy.2016.09.032

Fernando, A. L., Costa, J., Barbosa, B., Monti, A., \& Rettenmaier, N. (2017). Biomass and bioenergy environmental impact assessment of perennial crops cultivation on marginal soils in the Mediterranean region. Biomass and Bioenergy, 111, 174-186.

https://doi.org/10.1016/j.biombioe.2017.04.005

Garcia-Hurtado, E., Pey, J., Baeza, M. J., Carrara, A., Llovet, J., Querol, X., Alastuey, A., \& Vallejo,V. R. (2013). Carbon emissions in Mediterranean shrubland wildfires: An experimental approach. Atmospheric Environment, 69, 86-93. https://doi.org/10.1016/j.atmosenv.2012.11.063

Giorgi, F. (2006). Climate change hot-spots. Geophysical Research Letters, 33(8), 1-4. https://doi.org/10.1029/2006GL025734

Jebali, E., Essid, H., \& Khraief, N. 2017. The analysis of energy efficiency of the Mediterranean countries : A two-stage double bootstrap DEA approach. Energy, 134, 991-1000. https://doi.org/10.1016/j.energy.2017.06.063

Jeon, B. M., \& Sickles, R.C. (2004). The role of environmental factors in growth accounting. Journal of Applied Econometrics, 19(5), 567-591. https://doi.org/10.1002/jae.769

Kahouli, B. (2018). The causality link between energy electricity consumption, $\mathrm{CO}_{2}$ emissions, $\mathrm{R} \& \mathrm{D}$ stocks and economic growth in Mediterranean countries ( MCs ). Energy, 145, 388-399. https://doi.org/10.1016/j.energy.2017.12.136

Kaneko, S., \& Managi, S. (2004). Environmental productivity in China. Economics Bulletin, 17(2), 1-10.

Kumar, S. (2006). Environmentally sensitive productivity growth: A global analysis using MalmquistLuenberger index. Ecological Economics, 56(2), 280-293. https://doi.org/10.1016/j.ecolecon.2005.02.004

Li, W., Wang, W., Wang, Y., \& Ali, M. (2018). Historical growth in total factor carbon productivity of the Chinese industry: A comprehensive analysis. Journal of Cleaner Production, 170, 471-485. https://doi.org/10.1016/j.jclepro.2017.09.145

Liu, W., Zhan, J., Wang, C., Li, S., \& Zhang, F. (2018). Environmentally sensitive productivity growth of industrial sectors in the Pearl River Delta. Resources, Conservation and Recycling, 139(19), 50-63. https://doi.org/10.1016/j.resconrec.2018.07.017

Malmquist, S. (1953). Index numbers and indifference surfaces. Trabajos De Estadistica, 4, 209-242.

Mardani, A., Kazimieras, E., Streimikiene, D., \& Jusoh, A. (2016). A comprehensive review of data envelopment analysis (DEA) approach in energy efficiency. Renewable and Sustainable Energy Reviews, 70, 1298-1322. https://doi.org/10.1016/j.rser.2016.12.030

Mbarek, M. B., Saidi, K., \& Feki, R. (2018). How effective are renewable energy in addition of economic growth and curbing $\mathrm{CO}_{2}$ emissions in the long run ? A panel data analysis for four Mediterranean countries. Journal of the Knowledge Economy, 9(3), 754-766. https://doi.org/10.1007/s13132-016$\underline{0365-9}$

Monastyrenko, E. (2017). Eco-efficiency outcomes of mergers and acquisitions in the European electricity industry. Energy Policy, 107, 258-277. https://doi.org/10.1016/j.enpol.2017.04.030

Munisamy, S., \& Arabi, B. (2015). Eco-efficiency change in power plants: Using a slacks-based measure for the meta-frontier Malmquist-Luenberger productivity index. Journal of Cleaner Production, 105, 218232. https://doi.org/10.1016/j.jclepro.2014.12.081 
Oh, D. (2010). A global Malmquist-Luenberger productivity index: An Application to OECD countries 19902004. Journal of Productivity Analysis, 34(3), 183-197.

Ray, C., \& Desli, E. (1997). Productivity growth, technical progress, and efficiency change in industrialized countries: Comment. American Economic Association, 87(5), 1033-1039.

Sanz-Cobena, A., García-Marco, S., Quemada, M., Gabriel, J. L., Almendros, P., \& Vallejo, A. (2014). Do cover crops enhance $\mathrm{N} 2 \mathrm{O}, \mathrm{CO}_{2}$ or $\mathrm{CH}_{4}$ emissions from soil in Mediterranean arable systems? Science of the Total Environment, 466-467(1), 164-174. https://doi.org/10.1016/j.scitotenv.2013.07.023

Shen, N., Liao, H., Deng, R., \& Wang, Q. (2019). Different types of environmental regulations and the heterogeneous influence on the environmental total factor productivity: Empirical analysis of China's industry. Journal of Cleaner Production, 211, 171-184. https://doi.org/10.1016/j.jclepro.2018.11.170

Song, M., Zheng, W., \& Wang, S. (2017). Measuring green technology progress in large-scale thermoelectric enterprises based on Malmquist-Luenberger life cycle assessment. Resources, Conservation \& Recycling, 122, 261-269. https://doi.org/10.1016/j.resconrec.2017.03.001

Vilén, T., \& Fernandes, P. M. (2011). Forest fires in Mediterranean countries: $\mathrm{CO}_{2}$ emissions and mitigation possibilities through prescribed burning. Environmental Management, 48, 558-567. https://doi.org/10.1007/s00267-011-9681-9

Wang, H., Zhou, P., \& Zhou, D. Q. (2013). Scenario-based energy efficiency and productivity in China: A nonradial directional distance function analysis. Energy Economics, 4O, 795-803. https://doi.org/10.1016/j.eneco.2013.09.030

Wei, Y., Li, Y., Wu, M., \& Li, Y. (2019). The Decomposition of total factor $\mathrm{CO}_{2}$ emission efficiency of 97 contracting countries in Paris agreement. Energy Economics, 78, 365-378. https://doi.org/10.1016/j.eneco.2018.11.028

Yörük, B. K., \& Zaim, O. (2005). Productivity growth in OECD countries: A comparison with Malmquist indices. Journal of Comparative Economics, 33, 401-420.https://doi.org/10.1016/j.jce.2005.03.011

Zhang, C., Liu, H., Bressers, H. T. A., \& Buchanan, K. S. (2011). Productivity growth and environmental regulations-accounting for undesirable outputs: Analysis of China's thirty provincial regions using the Malmquist-Luenberger index. Ecological Economics, 7o(12), 2369-2379. https://doi.org/10.1016/j.ecolecon.2011.07.019

Zhang, N., \& Choi, Y. (2014). A note on the evolution of directional distance function and its development in energy and environmental studies 1997-2013. Renewable and Sustainable Energy Reviews, 33, 5059. https://doi.org/10.1016/j.rser.2014.01.064

Zhang, N., Bing, W., \& Zhongfei, C. (2016). Carbon emissions reductions and technology gaps in the world's factory, 1990-2012. Energy Policy, 91, 28-37. https://doi.org/10.1016/j.enpol.2015.12.042

Zhang, N., Bing, W., \& Zhu, L. (2016). Carbon emissions dynamics, efficiency gains, and technological innovation in China's industrial sectors. Energy, 99, 10-19. https://doi.org/10.1016/j.energy.2016.01.012

Zhou, P., Ang, B.W., \& Zhou, D.Q. (2012). Measuring economy-wide energy efficiency performance: A parametric frontier approach. Applied Energy, 90, 196-200. https://doi.org/10.1016/j.apenergy.2011.02.025

Zrelli, M. H. (2017). Dioxide emissions and economic growth in selected Mediterranean countries. Environmental Economics and Policy Studies, 19(4), 691-709. 
Jebali \& Essid, 2020

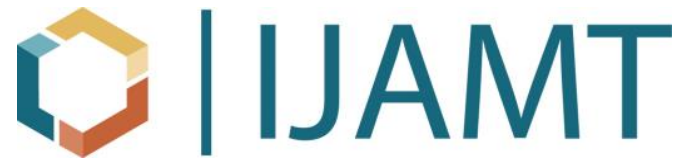

The International Journal of Applied Management and Technology (IJAMT), sponsored by Walden University's College of Management and Technology, is a peer-reviewed, online journal that addresses contemporary national and international issues related to management and technology. 